Y/DX-2434

\title{
UNCERTAINTY OF PYROMETERS IN A CASTING FACILITY
}

\section{Y-12 \\ NATIONAL SECURITY COMPLEX}

\author{
D. K. Mee \\ J. E. Elkins \\ R. M. Fleenor \\ J. M. Morrison \\ M. W. Sherrill \\ Y-12 National Security Complex \\ L. E. Seiber \\ Oak Ridge National Laboratory
}

December 7, 2001

\section{LIMITED DISTRIBUTION}

Prepared by the

Y-12 National Security Complex

P. O. Box 2009, Oak Ridge, Tennessee 37831-8169

managed by

BWXT Y-12, L.L.C.

for the

U.S. DEPARTMENT OF ENERGY

under contract DE-AC05-00OR22800 


\title{
UNCERTAINTY OF PYROMETERS IN A CASTING FACILITY
}

\author{
D. K. Mee \\ J. E. Elkins \\ R. M. Fleenor \\ J. M. Morrison \\ M. W. Sherill \\ Y-12 National Security Complex \\ L. E. Seiber \\ Oak Ridge National Laboratory
}

December 7, 2001

\section{LIMITED DISTRIBUTION}

Prepared by the

Y-12 National Security Complex

P. O. Box 2009, Oak Ridge, Tennessee 37831-8169

managed by

BWXT Y-12, L.L.C.

for the

U.S. DEPARTMENT OF ENERGY

under contract DE-AC05-00OR22800 


\section{DISCLAIMER}

This report was prepared as an account of work sponsored by an agency of the United States Government. Neither the United States Government nor any agency thereof, nor any of their employees, makes any warranty, express or implied, or assumes any legal liability or responsibility for the accuracy, completeness, or usefulness of any information, apparatus, product, or process disclosed, or represents that its use would not infringe privately owned rights. Reference herein to any specific commercial product, process, or service by trade name, trademark, manufacturer, or otherwise, does not necessarily constitute or imply its endorsement, recommendation, or favoring by the United States Government or any agency thereof. The views and opinions of authors expressed herein do not necessarily state or reflect those of the United States Government or any agency thereof. 


\section{CONTENTS}

MANAGEMENT SUMMARY …......................................................... 1

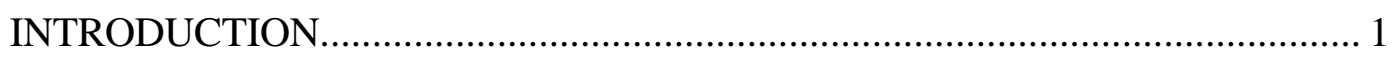

CERTIFICATION UNCERTAINTY …..................................................... 2

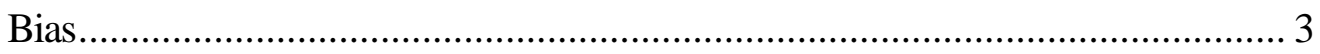

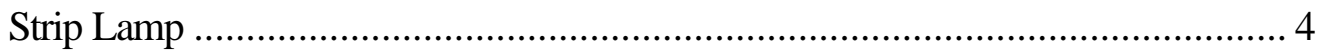

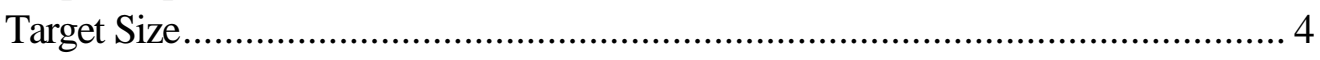

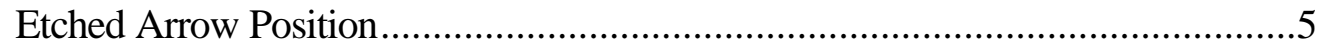

Order of Certification Points.........................................................................5

Thermal Equilibrium...............................................................................

Ambient Temperature............................................................................6

Pyrometer Wavelength..........................................................................6

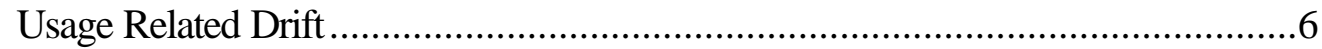

Digital Pyrometer Working Standard ....................................................... 7

Disappearing Filament Pyrometers ........................................................ 8

Production Certified Digital Pyrometer.......................................................... 9

Production Certified Two-Color Optical Pyrometer ...................................... 10

BRIGHTNESS PYROMETER UNCERTAINTY IN PROCESS

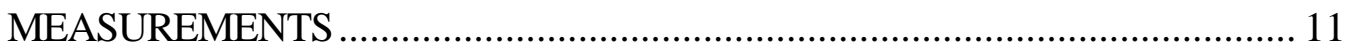

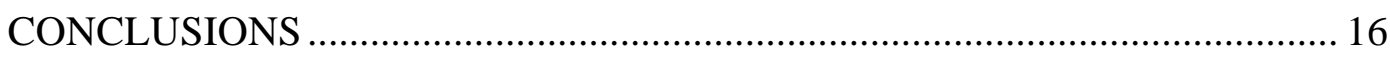

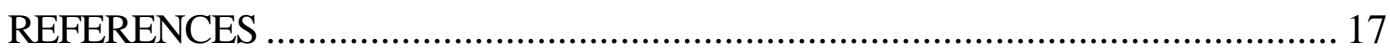

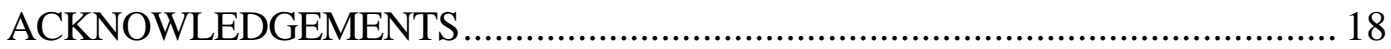




\section{MANAGEMENT SUMMARY}

Casting furnaces at the Y-2 National Security Complex use hand-held brightness pyrometers to control furnace temperatures. Because temperature control is important to ensure properties of cast weapon parts, pyrometer certification uncertainties have been estimated based on previous experimental data. Certification uncertainty sources from primary standards, transfer standards, production pyrometers, and measurement drift were considered. The analysis focuses on hand-held filament brightness pyrometers used traditionally for furnace control and on hand-held digital pyrometers currently under evaluation. Automatic two-color pyrometers installed in the early 1990s are addressed briefly. The results of this analysis indicate that filament pyrometer uncertainty is $\pm 20.5^{\circ} \mathrm{C}$, which is larger than traditional expectations. The larger uncertainty is due, in part, to the addition of a transfer standard that became necessary when contaminated instruments had to be certified at the field site. This analysis showed that the newer, digital brightness pyrometers have certification uncertainties of $\pm 12^{\circ} \mathrm{C}$ or $\pm 18^{\circ} \mathrm{C}$ depending on whether the instrument is certified at the Y-12 Standards Laboratory or in the field. This report also addresses uncertainties related to the production furnace. A bias of $-19.4^{\circ} \mathrm{C}$ in production furnace measurements is attributed to the use of Pyrex ${ }^{\mathrm{TM}}$ windows and window fogging. A $2 \sigma$ variation of $28.6^{\circ} \mathrm{C}$ early in the hold period is discussed, which is caused by emissivity variation and reflection.

\section{INTRODUCTION}

Disappearing filament pyrometers have been traditionally used by the Enriched Uranium Operations (EUO) Organization to control casting furnace temperatures. In the 1980s, these pyrometers were sent to the Y-12 Standards Laboratory for certification on a strip lamp.

Significant questions exist as to how the previous uncertainty limits were determined. Traditionally, disappearing filament pyrometers used in production areas for casting line temperature measurements had a stated uncertainty of $\pm 10^{\circ} \mathrm{C}$. A similar type of disappearing filament pyrometer certified by the National Institute of Standards and Technology (NIST) and handled as a primary standard also had a $\pm 10^{\circ} \mathrm{C}$ uncertainty.* If a primary standard certified by NIST carried a $\pm 10^{\circ} \mathrm{C}$ uncertainty, it is not reasonable to assume that a Y-12 Standards Laboratory certified instrument, which was handled as a working instrument on furnaces, could hold the same specification. Therefore, a new determination of uncertainty for pyrometers used by EUO for furnace temperature measurement is in order.

In addition to questions as to the uncertainty of traditional certifications, there have been changes in the production pyrometers as well as in calibration techniques. In 1988, automatic two-color pyrometers were added to production furnaces. ${ }^{1}$ Calibration of these units was difficult. Pyrometer optic heads and circuit boards had to be removed from the production area for certification at the Y-12 Standards Laboratory. At that time, the automatic pyrometers were certified on a tube furnace using a type-S thermocouple standard.

To make certification easier, in 1990 a tube furnace was purchased for the production area so certifications could be performed without removing pyrometers. An optical fiber thermometer was purchased to serve as a working standard during certifications. Introduction of a working standard in

* Configuration Station Guide: PES-0024, TIL147 
the calibration chain did cause some additional uncertainty, but benefits were significant. Production area certifications eliminated contamination, security, and calibration delay problems. Contamination control levels have become more stringent since that time and most older pyrometers can no longer be transferred to the Y-12 Standards Laboratory.

The optical fiber thermometer working standard ultimately proved to be unreliable and was replaced with a digital brightness pyrometer. This digital pyrometer was used as a transfer standard in the work presented in this report. Performance of the digital brightness pyrometer has been good. A second unit was purchased for evaluation as a possible replacement for the older disappearing filament pyrometers.

Much of the data used in the uncertainty evaluations of this report were collected from a one-year period (FY 1999) soon after resumption of operations after a stand down. Information for determining automatic pyrometer uncertainty was taken from 1987 data collected as the pyrometers were being evaluated. Data from 1987 also allowed comparison of operator disappearing filament and immersion thermocouple temperature measurements ${ }^{2}$ which proved useful in evaluating uncertainty related to the production furnace.

\section{CERTIFICATION UNCERTAINTY}

The objective of this work is to determine estimates of uncertainty for production casting temperature measurements. The approach used is described in the NIST Technical Note 1297, Guidelines for Evaluating and Expressing the Uncertainty of NIST Measurement Results. ${ }^{3}$ In this approach, each component that contributes to the uncertainty of a measurement is identified and a value for the component (in standard deviation form) is estimated from whatever sources are available.

Traditionally, disappearing filament pyrometers have been used by EUO for control of furnace temperatures. These pyrometers are now obsolete and vendor support has been discontinued. However, evaluation of the instrument is still considered important because EUO continues to use them for furnace control. During FY 1997, a hand-held digital pyrometer identical to the digital pyrometer working standard was purchased for evaluation as a possible replacement to pyrometers used in production. Both disappearing filament and digital brightness pyrometers are evaluated in this document.

Ten main components were identified in determining the uncertainty of certified pyrometers when measuring strip lamps or tube furnaces. In the first part of this document these "certification uncertainties" will be discussed. The ten components are as follows:

1. Strip lamp radiance temperature uncertainty (sub-components discussed but quoted uncertainty used).

2. Lack of agreement of digital pyrometer in measuring the strip lamp primary standard.

3. Uncertainty caused by differences in wavelength between the digital pyrometer and NIST's certification pyrometer.

4. Transmission loss uncertainty when using a close focus lens to certify digital pyrometers on a strip lamp.

5. Drift of the digital pyrometer over the period between certifications. 
6. Lack of agreement between disappearing filament pyrometers and the digital pyrometer working standard.

7. Drift in disappearing filament pyrometers between certifications.

8. Lack of agreement between a field certified digital pyrometer and the digital pyrometer working standard.

9. Lack of agreement between two-color automatic pyrometers and the digital pyrometer working standard.

10. Drift in two-color automatic pyrometers between certifications.

Uncertainty sub-components within each of these ten components exist but are not necessarily addressed in this report. Data used in this analysis for estimating each component include the contribution of subcomponents. Sub-components are discussed for the strip lamp radiance uncertainty because they are useful in defining appropriate technique. However, the total strip lamp uncertainty quoted by the Y-12 Standards Laboratory is used in the analysis.

Table 1 contains the results of the analysis for each component and provides the $2 \sigma$ confidence interval for each instrument, including standard uncertainty and drift over the certification period. Random uncertainty is converted to a $2 \sigma$ value before being entered on the table. Table 1 provides a convenient reference during the discussion of calibration uncertainty. Process-related uncertainty is discussed later and is not included in the table.

\section{Table 1. Calibration uncertainty for production area pyrometers and standards $(2 \sigma$ level)}

\begin{tabular}{|c|c|c|c|c|c|}
\hline Instrument & $\begin{array}{c}\text { Range } \\
\left({ }^{\circ} \mathbf{C}\right)\end{array}$ & $\begin{array}{c}\text { Source of } \\
\text { Uncertainty }\end{array}$ & $\begin{array}{l}\text { Bias } \\
\left({ }^{\circ} \mathbf{C}\right)\end{array}$ & $\begin{array}{l}\text { 2F Random } \\
\text { Uncertainty } \\
\quad\left({ }^{\circ} \mathrm{C}\right)\end{array}$ & $\begin{array}{c}\mathbf{2 F} \\
\text { Calibration } \\
\text { Uncertainty } \\
\text { Including } \\
\text { Standards } \\
\left({ }^{\circ} \mathrm{C}\right)\end{array}$ \\
\hline \multirow[t]{3}{*}{ Primary Strip Lamp } & \multirow[t]{3}{*}{$\begin{array}{l}800- \\
1800\end{array}$} & $\begin{array}{l}\text { Stated NIST } \\
\text { Uncertainty }\end{array}$ & 0.0 & 0.6 & \multirow[t]{3}{*}{$(+5.0,-5.0)$} \\
\hline & & $\begin{array}{l}\text { Deviations from NIST } \\
\text { Orientation and } \\
\text { Operation }\end{array}$ & 0.0 & 2.2 & \\
\hline & & Drift & -0.5 & 0.6 & \\
\hline \multirow[t]{4}{*}{$\begin{array}{l}\text { Digital Pyrometer } \\
\text { Working Standard }\end{array}$} & \multirow[t]{4}{*}{$\begin{array}{l}1000- \\
1400\end{array}$} & $\begin{array}{l}\text { Disagreement from } \\
\text { Primary Standard }\end{array}$ & 0.0 & 3.7 & \multirow[t]{4}{*}{$(+8.5,-12.7)$} \\
\hline & & $\begin{array}{l}\text { Wavelength Related } \\
\text { Error }\end{array}$ & -0.7 & 0.8 & \\
\hline & & $\begin{array}{l}\text { Close focus lens } \\
\text { transmission } \\
\text { uncertainty }\end{array}$ & 0.0 & 1.3 & \\
\hline & & Drift & -3.5 & 5.6 & \\
\hline
\end{tabular}




\begin{tabular}{|c|c|c|c|c|c|}
\hline \multirow[t]{2}{*}{$\begin{array}{l}\text { Disappearing } \\
\text { Filament Pyrometer }\end{array}$} & \multirow[t]{2}{*}{$\begin{array}{l}1000- \\
1400\end{array}$} & $\begin{array}{l}\text { Disagreement with } \\
\text { Working Standard }\end{array}$ & -1.2 & 7.1 & \multirow[t]{2}{*}{$(+15.1,-20.5)$} \\
\hline & & Drift & 0.0 & 10.3 & \\
\hline \multirow{2}{*}{$\begin{array}{l}\text { Digital Pyrometer } \\
\text { Certified via } \\
\text { Working Standard }\end{array}$} & \multirow[t]{2}{*}{$\begin{array}{l}1000- \\
1400\end{array}$} & $\begin{array}{l}\text { Disagreement with } \\
\text { Working Standard }\end{array}$ & 0.0 & 2.2 & \multirow[t]{2}{*}{$(+10.4,-18.1)$} \\
\hline & & Drift & -3.5 & 5.6 & \\
\hline \multirow{2}{*}{$\begin{array}{l}\text { Two-Color } \\
\text { Automatic } \\
\text { Pyrometers }\end{array}$} & \multirow[t]{2}{*}{$\begin{array}{l}1000- \\
1400\end{array}$} & $\begin{array}{l}\text { Disagreement with } \\
\text { Working Standard }\end{array}$ & +0.5 & 2.6 & \multirow[t]{2}{*}{$(+13.0,-16.7)$} \\
\hline & & Drift & 0.0 & 8.8 & \\
\hline
\end{tabular}

\section{Strip Lamp}

The primary standard used to relate production temperature measurements to NIST temperature standards is a strip lamp. The primary standard used (M247478) had an uncertainty of $\pm 0.9^{\circ} \mathrm{C}$ to a $3 \sigma$ level assuming that the orientation and operation used in the Y-12 Standards Laboratory are identical to those used in the NIST facility. ${ }^{4}$ A document attached to the Report of Calibration describes the expected orientation and operational conditions which are summarized by the following list: ${ }^{5,6}$

1. Alignment

(a) Base down,

(b) Notch side of filament vertical (as viewed from pyrometer),

(c) Pyrometer sighted on center of the filament at the elevation of the notch (adjusted throughout test),

(d) Target area is $0.6 \mathrm{~mm}$ wide and $0.8 \mathrm{~mm}$ high,

(e) Optical axis of pyrometer is horizontal,

(f) Etched arrow on the opposite side of lamp from pyrometer,

(g) Lamp is positioned so that etched arrow is viewed at the center of the notch by pyrometer, and

(h) Alignment performed when radiance temperature is $1700^{\circ} \mathrm{C}$.

2. Calibration points are ordered from higher temperature to lower temperature.

3. Lamp is in thermal equilibrium when data are taken.

4. Ambient temperature of $23 \pm p^{\circ} \mathrm{C}$.

5. Lamp base temperature is not controlled.

6. Lamp kept clean.

7. Pyrometer acceptance angle is $4.4^{\circ}$.

8. Pyrometer filter wavelength is $655.7 \mathrm{~nm}$.

9. Lamp operating on direct current with the longer filament post at the positive potential.

Potential error sources caused by deviations from the expected criteria for using the strip lamp will now be discussed.

\section{Target Size}

First, the target size was much larger. The strip lamp filament thickness was measured to be $0.053 \geq 0.00$ in. at the notch (total filament thickness was 0.059 in. away from notch). Focusing on this type filament required modification of the digital pyrometer optics to reduce the target spot size. The spot size 
of a modified digital pyrometer was calculated as $0.047 \mathrm{in}$. using the minimum focal distance of the first modified pyrometer (14- in. for M259774). Instruments purchased later used a close focus lens during certification to obtain this focus distance. For these instruments, the target diameter is the focal distance divided by 300 . Movement of the target position to the left or right on the strip lamp filament did not cause a change in the observed reading. Therefore it is deemed sufficiently small to make the measurement even though the target width was twice the dimension used by the NIST ( 0.023 -in. spot width).

\section{Etched Arrow Position}

There is some question of alignment observed in these tests. On the initial certifications, the lamp base had to be cocked significantly to get the etched arrow aligned in the filament notch. Before conducting later certifications, the lamp base was found off the track. When the base was placed on the track, the large adjustment of lamp position was not required. However, both calibrations are considered valid because the etched arrow was viewed in the notch.

\section{Order of Certification Points}

Certification points were not always approached from a higher temperature when certifying the working standards. NIST states that errors of $1^{\circ} \mathrm{C}$ can be encountered if certification is not done from the highest to the lowest temperature. Tests performed at Y-12 confirmed errors in this range. In this effort, the initial certifications maintained the proper order, but the second certifications were not. Using the technique described in Section 4.6 of NIST Note 1297, this error is estimated with a standard deviation of $0.3^{\circ} \mathrm{C} .{ }^{3} \mathrm{~A}$ modification to the metrology calibration test procedure has been made to require certification from high to low temperatures consistent with the NIST procedure.

\section{Thermal Equilibrium}

Before the initial calibration, a test was conducted to evaluate how long it would require to gain stability. Power was held on the filament until the measured brightness temperature did not change for $4 \mathrm{~m}$ (pyrometer had $1{ }^{\circ} \mathrm{C}$ resolution). The time for the strip lamp brightness temperature to stabilize is shown in Fig. 1. It should be noted that, at times, the power to the filament would drift slightly, requiring adjustment that extended the time to stability. This problem made the results shown in the figure somewhat variable. One set of data was collected from 900 to $2300^{\circ} \mathrm{C}$ followed by a second data set collected from 2300 to $900^{\circ} \mathrm{C}$. Based on this data, a hold time of $6 \mathrm{~m}$ is recommended when certifying points at $\$ 1200^{\circ} \mathrm{C}$ (point at $2300^{\circ} \mathrm{C}$ is not required). For points $<1200^{\circ} \mathrm{C}$, it is probably wise to use a 12 $\mathrm{m}$ hold. Using the technique described in Section 4.6 of NIST Note 1297, this error is estimated with a standard deviation of $0.6^{\circ} \mathrm{C}^{3}$ 


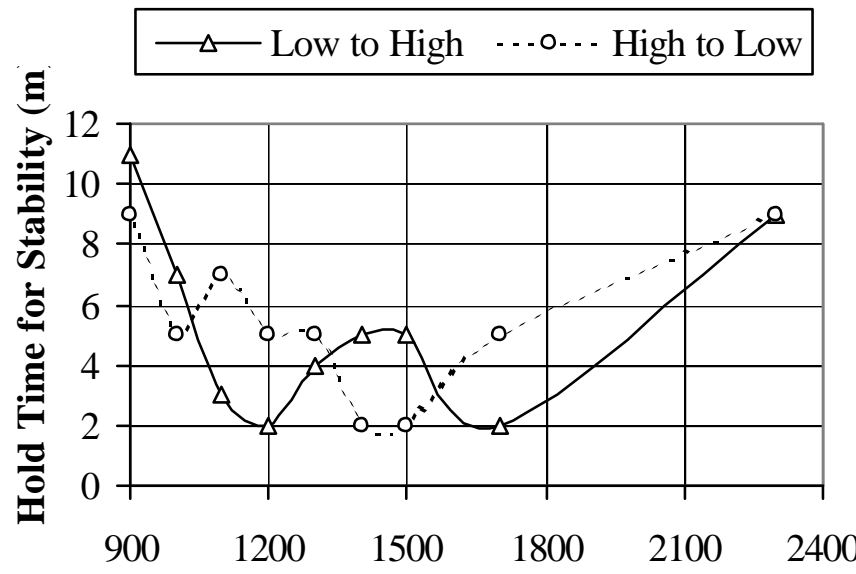

Certification Temperature (C)

Fig. 1. Hold time for strip lamp stability.

\section{Ambient Temperature}

Barber has noted changes of up to $0.4^{\circ} \mathrm{C}$ for every $1^{\circ} \mathrm{C}$ change in room temperature primarily at the low end of the digital pyrometer range. ${ }^{6}$ These changes would be significant at $1000^{\circ} \mathrm{C}$ because the ambient temperature of the Y-12 Standards Laboratory is not well controlled. Temperature changes in the laboratory are estimated at $6{ }^{\circ} \mathrm{F}\left(3.3^{\circ} \mathrm{C}\right)$ in a day. However, temperatures of up to $90^{\circ} \mathrm{F}\left(32^{\circ} \mathrm{C}\right)$ and down to $62^{\circ} \mathrm{F}\left(17^{\circ} \mathrm{C}\right)$ have been observed in the past. If certifications are limited to ambient conditions of $23 \pm 4^{\circ} \mathrm{C}$, then the worst case effect on the measured radiance temperature throughout the range of interest would be bounded by $\pm 1.6^{\circ} \mathrm{C}$. Using the technique described in Section 4.6 of NIST Note 1297, this uncertainty is estimated with a standard deviation of $0.9^{\circ} \mathrm{C} .{ }^{3}$ Because the temperature excursion is equally likely to be in either direction, no bias is included in this estimate. The $23 \pm 47^{\circ} \mathrm{C}$ temperature limit has been placed in the metrology calibration test procedure. It is recommended that temperature control be provided for this laboratory.

\section{Pyrometer Wavelength}

The wavelength of the digital pyrometer is at $650 \mathrm{~nm}$, rather than $655.7 \mathrm{~nm}$ in the NIST measurement. This uncertainty is addressed in the analysis of the working standard.

\section{Usage Related Drift}

In addition to technique-related errors, NIST states that the radiance temperature from the lamp should be decreased $1{ }^{\circ} \mathrm{C}$ overall temperatures for every 10 hours of operation at $2300^{\circ} \mathrm{C}$; however, this time was not approached in practice. The vendor of the digital pyrometer indicated that the calibration point at $2300^{\circ} \mathrm{C}$ was unnecessary if the instrument certification range did not exceed $1700^{\circ} \mathrm{C}$. Elimination of this 
calibration point is being considered to prolong the life of the strip lamp. For the purpose of this analysis, it is assumed that the uncertainty will be limited between 0 and $1^{\circ} \mathrm{C}$. Using NIST Note 1297 , Section 4.6, this uncertainty is estimated with a random component having a standard deviation of $0.3^{\circ} \mathrm{C}$ and a bias of $-0.5^{\circ} \mathrm{C}^{3}$

The Y-12 Standards Laboratory quotes an uncertainty of $\pm 8^{\circ} \mathrm{C}$ for the primary strip lamp between the ranges of 800 and $2300^{\circ} \mathrm{C}$. Combining the standard deviations in this section as the root of the sum of the squares provides a total $2 \sigma$ random uncertainty of $2.4^{\circ} \mathrm{C}$ with a bias of $-0.5^{\circ} \mathrm{C}$. The recommendations discussed in this section have been implemented as a matter of good practice, which will result in further reduction in the strip lamp uncertainty. Sub-components of this section are included in Table 1. Because the Y-12 Standards Laboratory is the authority in this case, the $\pm 5^{\circ} \mathrm{C}$ number is used for total strip lamp uncertainty in the table. Sub-components are placed in italics indicating that they were not used to derive the total uncertainty.

\section{Digital Pyrometer Working Standard}

During FY1998, the digital pyrometer became the working standard of choice for certifying production pyrometers. Special lenses were ordered with the initial pyrometers to allow certification on the primary strip lamp, as previously discussed. Close focus certification lenses were purchased later that allow either custom focus range (14 to 53 in.) or standard focus range (28 in. to infinity) pyrometers to be certified on a strip lamp. Y-12 Standards Laboratory data using a strip lamp to certify the digital pyrometer is minimal. Data in this document is based on two instruments that were certified twice on a lamp. One of these instruments is a working standard (M-213327) and the other is an instrument being evaluated for use on production furnaces (M-259774). As-left and as-found values are available for the last certification of each instrument. Certifications occurred between 13 and 15 months apart, with data collected at $1000,1100,1200,1300,1400^{\circ} \mathrm{C}$. To estimate nonconformity to the primary strip lamp, asleft results from both instruments over all five temperatures were combined to give 15 values. The final set of data for the operation's evaluation instrument was not included because no attempt was made to adjust this instrument to correct errors up to $-8^{\circ} \mathrm{C}$ in the range of interest. This deficiency has been corrected by modifying the metrology calibration test procedure to require an adjustment if the agreement exceeds the manufacturer's specification in the range of interest $\left( \pm 0.25 \%\right.$ of measurement for $1000^{\circ} \mathrm{C}$ and over). The mean of the 15 values was $-1.0^{\circ} \mathrm{C}$ with a standard deviation of $1.8^{\circ} \mathrm{C}$. The average was statistically significant from zero. However, the digital pyrometer has the capability of adjusting the whole curve up or down in $1^{\circ} \mathrm{C}$ increments. Instructions have been added to the metrology calibration test procedure to allow adjustment of the mean error to near zero. The digital instrument specification accuracy over the range of interest $\left( \pm 3.5^{\circ} \mathrm{C}\right)$ is close to that determined by using the limited data set $(2 \sigma$ uncertainty of $\pm 3.7^{\circ} \mathrm{C}$ ) which adds credibility to determination. The value obtained from the data $\left( \pm 3.7^{\circ} \mathrm{C}\right)$ is used as a $2 \sigma$ uncertainty interval in this analysis.

Uncertainty also exists because the digital pyrometer measures the primary strip lamp radiance temperature at a different wavelength from that used by NIST in certifying the lamp. The strip lamp calibration report from NIST ${ }^{4}$ relates radiance temperature at $655.7 \mathrm{~nm}$ to direct current. Because the digital pyrometer measures temperature at a wavelength of $650 \mathrm{~nm}$ and uses a much wider filter, an additional uncertainty must be included. The vendor indicated in a telephone conversation on October 7,1999 , that both the difference in filter center frequency and width makes about a $-0.1 \%$ of reading difference at $1400^{\circ} \mathrm{C}$, which decreases linearly as the measurement temperature decreases. Using NIST Note 1297, Section 4.6, this uncertainty is estimated with a random component having a standard 
deviation of $0.40^{\circ} \mathrm{C}$ and a bias of $-0.7^{\circ} \mathrm{C} .^{3}$

Originally, digital pyrometers were purchased which had a range of roughly 14 to 53 in.. This range was sufficient to allow certification on a strip lamp and use in the field. When the purchase of additional instruments was attempted, the manufacturer stated that they could not replicate this range. Additional instruments were purchased with a standard range (28 in. to infinity) and a close focus lens that was to be used during certification. When certifying with a close focus lens, the digital pyrometer emissivity must be reduced to 0.94 to compensate for transmission losses in the lens. This factor is marked on the lens and was verified to the extent possible by the Y-12 Standards Laboratory using a tube furnace. Unfortunately, calibration is made more difficult by the lens because the software calibration routine cannot accommodate emissivities less than 1.0. Calibration requires raising the strip lamp radiance temperature to compensate for the loss in transmission through the close focus lens. Currents were derived by fitting the strip lamp radiance temperature vs. current data with a polynomial and calculating the additional current needed to compensate for lens transmission losses. The procedure, which was recommended by the manufacturer, proved successful. Following the calibration, a certification is performed using current values provided by NIST. For the purpose of this analysis, the uncertainty in transmission of the lens must be considered. The manufacturer stated that the $2 \sigma$ uncertainty in emissivity was $1 \%$. A table provided by the manufacturer indicates that a $1 \%$ error in emissivity causes a $0.5^{\circ} \mathrm{C}$ error at $800^{\circ} \mathrm{C}$ which increases to $1.3^{\circ} \mathrm{C}$ at $1400^{\circ} \mathrm{C}$. Because a correction is made for the expected loss in transmission, only maximum random uncertainty of $1.3^{\circ} \mathrm{C}$ needs to be considered in Table 1.

While the procedure using the close focus lens was suggested by the manufacturer, it is not the preferred technique. If funding were available, purchase of a $1 / 8 \%$ transfer standard would permit certification on a tube furnace. The manufacturer uses this type certification that eliminates the need for close focus lenses and tedious alignment of a strip lamp.

To estimate drift of the working standard over the calibration period, differences between the first certification as-left data and the second certification as-found data were calculated. The average of the 10 values was $-3.5^{\circ} \mathrm{C}$ with a standard deviation of $2.8^{\circ} \mathrm{C}$. The minus indicates a lower temperature reading at the end of the calibration period. The average was statistically lower than zero; therefore, a systematic error of $-3.5^{\circ} \mathrm{C}$ is included in the error analysis along with the random uncertainty.

\section{Disappearing Filament Pyrometers}

Four disappearing filament pyrometers have been certified in the first year after restarting the production casting facility. Data from the four pyrometers certified every two to three months from June 1988 to May 1999 (five calibrations) are used in this analysis. As-found and as-left data are available for all except the first certification. Instruments are certified at $1020,1100,1200,1300$, and $1400^{\circ} \mathrm{C}$. To estimate agreement between disappearing filament pyrometers and the digital pyrometer working standard, the 100 available as-left data points were combined. The average was $-1.2^{\circ} \mathrm{C}$ with a standard deviation of $3.6^{\circ} \mathrm{C}$. The minus indicated the digital pyrometer values were lower than working standard values. The average was statistically lower than zero; therefore, a bias of $-1.2^{\circ} \mathrm{C}$ is included in the error analysis.

To determine disappearing pyrometer drift over the certification period, the difference between each 
instrument's as-left and the following as-found data was calculated for each measurement temperature. This resulted in 80 differences, with an average of $-0.7^{\circ} \mathrm{C}$ and a standard deviation of $5.2^{\circ} \mathrm{C}$. The average was not statistically different from zero, so no bias is warranted in the analysis.

To obtain a total certification uncertainty for a disappearing filament pyrometer value at any time during the certification period, all the standard deviations are combined in the root-sum-of-squares technique described in the NIST publication. ${ }^{3}$ The resulting $2 \sigma$ value was $\pm P 5.1^{\circ} \mathrm{C}$. Since there were three means significantly different from zero, it is not appropriate to ignore them. They were added algebraically, giving a value of $-5.4^{\circ} \mathrm{C}$, then combined with the $\$ 15.1^{\circ} \mathrm{C}$ value to give limits of $\left(+15.1^{\circ} \mathrm{C},-20.5^{\circ} \mathrm{C}\right)$. This interval should be compared to the uncertainty interval of the disappearing filament brightness pyrometers with working standard uncertainty removed, $\left(+13.5^{\circ} \mathrm{C},-14.7^{\circ} \mathrm{C}\right)$ to determine the affect of introducing a working standard for certifying pyrometers in the production area. Because these limits are not symmetric, the worst case is used to express the uncertainty. A statement can be made that "a production area certified disappearing filament pyrometer can measure tube furnace temperatures during the certification period to within $\pm 20.5^{\circ} \mathrm{C}$ of the "real temperature." Process furnace-related uncertainty will be addressed later in this report.

\section{Production Certified Digital Pyrometer}

An uncertainty estimate for a digital pyrometer certified in the production area using the digital pyrometer working standard should be made. Only one test has been made using two digital pyrometers on a tube furnace, so this data is used to estimate what disagreement would be present for this type calibration. In this test, two instruments were received from the vendor and calibrated against a thermocouple standard on the Y-12 Standards Laboratory's tube furnace. Nine pairs of points are available. Five points were taken with the two pyrometers alternating at each calibration temperature. Four points were taken with the same instrument completing calibration points consecutively before changing pyrometers. Figure 2 shows the difference in two instrument responses. The good correlation between the linearity in these two instruments improves this certification. The mean difference between the two instrument readings for temperatures between 1000 and $1400^{\circ} \mathrm{C}$ was 0.2 , which is not significant. The standard deviation between the measurements was $1.10^{\circ} \mathrm{C}$, which is reported in Table 2 for deviation from the working standard. There are no wavelength differences when certifying one digital pyrometer with another. In addition, the tube furnace should have emissivities of unity for all wavelengths being considered. Therefore, the wavelength uncertainty does not need to be included for the production area certification. The drift should not be affected by the calibration technique, so it is repeated for this instrument. The total uncertainty interval including standards for a digital pyrometer certified in the production area is $\left(+10.4^{\circ} \mathrm{C},-18.1^{\circ} \mathrm{C}\right)$. This interval should be compared to the uncertainty interval of the digital pyrometer certified on a strip lamp $\left(+8.5^{\circ} \mathrm{C},-12.7^{\circ} \mathrm{C}\right)$ when deciding whether to certify the digital pyrometer in the production area or at the Y-12 Standards Laboratory. 


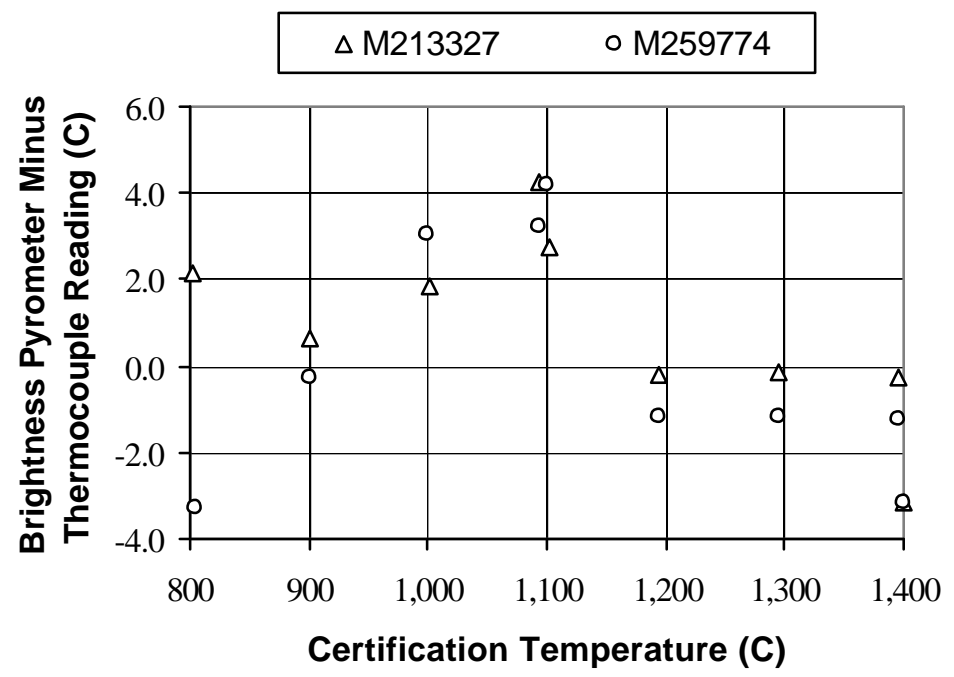

Fig. 2. Comparison of two digital brightness pyrometers using a tube furnace.

\section{Production Certified Two-Color Optical Pyrometer}

Data for determining the uncertainty of automatic two-color pyrometers were collected in late 1989 and early 1990. Certifications were performed using a tube furnace at the Y-12 Standards Laboratory and a thermocouple standard. Twenty-seven instrument calibrations are available with certification points at $1000,1100,1200,1300$, and $1400^{\circ} \mathrm{C}$. These 135 points had a standard deviation of $1.3^{\circ} \mathrm{C}$ and a mean of $+0.5^{\circ} \mathrm{C}$. The positive mean is significant and indicates that the optical measurement was higher than the thermocouple standard. The mean and $2 \sigma$ limits are reported in Table 1. Two-color pyrometers should be certified by the digital pyrometer working standard in the production area rather than using a thermocouple standard at the Y-12 Standards Laboratory, however, the above data is all that is available for making this estimate. Because the automatic pyrometers are not currently in operation, no data is available to evaluate the drift component. This estimate was made using comments by a vendor technician who claimed that drift would typically range between 3 to $5^{\circ} \mathrm{C}$ when using a one-year certification period. Using the technique described in Section 4.6 of NIST Note 1297, this uncertainty is estimated with a standard deviation of $4.4^{\circ} \mathrm{C} .{ }^{3}$ Combining the lack of agreement with the working standard drift and standard uncertainty gives a $2^{\circ}$ uncertainty interval of $\left(+13.0^{\circ} \mathrm{C},-16.7^{\circ} \mathrm{C}\right)$. 


\section{BRIGHTNESS PYROMETER UNCERTAINTY IN PROCESS MEASUREMENTS}

The previous discussion dealt with uncertainty pyrometers when measuring carefully controlled strip lamps or tube furnaces that have emissivities near 1.00. The subject addressed in this section is uncertainty in a measurement of molten-metal temperature in a production furnace using either filament or digital brightness pyrometers. There are many additional error sources that can cause a well-calibrated instrument to give a poor process measurement. These process-related sources are described in Table 2.

Data is not available to separately analyze each component in Table 2. However, some data taken during 1987 using hand held filament pyrometers is useful in characterizing the total measurement uncertainty of brightness pyrometers measuring furnace temperatures. This data was originally collected to determine the accuracy of various two-color pyrometers using a type-S immersion thermocouple measurement as a standard. Immersion thermocouple uncertainty in this data set should not be greater than $" 10^{\circ} \mathrm{C}$. Various components contributing to this uncertainty are discussed in a 1983 report. $^{2}$

The estimate of uncertainty, while measuring production furnace temperatures, can be made by comparing the filament pyrometer readings to the thermocouple standard, as shown in Fig. 3. A bias of $-19.4^{\circ} \mathrm{C}$ exists in the data set. The most significant factors contributing to this bias are the use of a Pyrex ${ }^{\mathrm{TM}}$ window, window fogging, and perhaps temperature gradients in the melt. The Pyrex ${ }^{\mathrm{TM}}$ window has been shown to decrease a brightness pyrometer's measurement $-11.2^{\circ} \mathrm{C}$ when measuring furnace temperatures at $1300^{\circ} \mathrm{C}$. Subsequent to this data set, Pyrex ${ }^{\mathrm{TM}}$ windows were replaced by quartz windows that are also used in the certification process to compensate for window error.

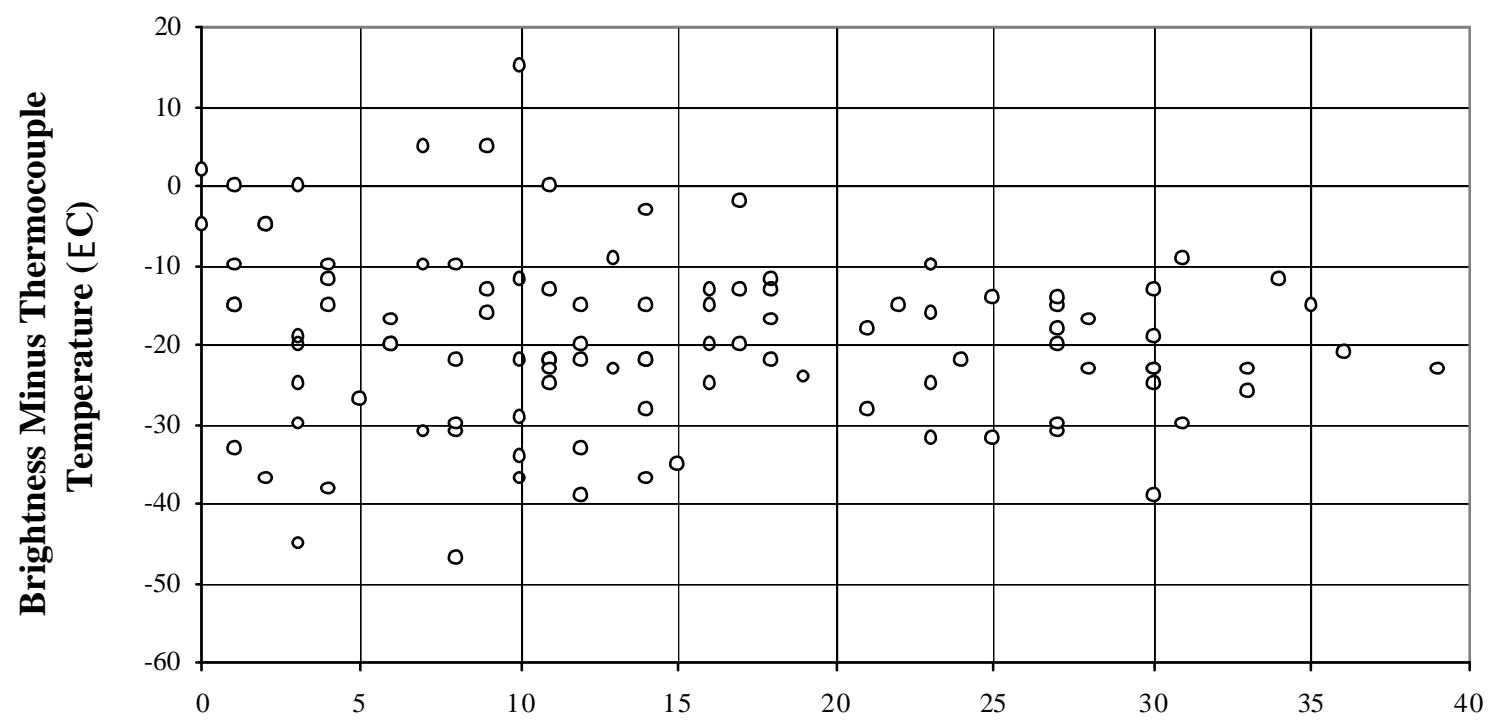

Time from Extrapolated Start of Hold (m)

Fig. 3. Dynamic filament brightness pyrometer error using type-S thermocouple standard. 
Additionally, window fogging has been shown to contribute significant error. To test for the magnitude of error expected due to fogging, three of the dirtiest windows were removed from consolidation runs in October 1999. The effect of the fogged window was tested by reading temperatures with no window, with a fogged window, and through the same window after cleaning. The difference in the temperature suppression of the fogged and cleaned window should be a rough indication of the error introduced by the fogging of the window. Results of the test indicated that fogging induced errors of $-8,-14$, and $19^{\circ} \mathrm{C}$. This brief test was not very rigorous. The $-8^{\circ} \mathrm{C}$ value was obtained by viewing a fluorescent light through the window rather than the furnace melt. The $-14^{\circ} \mathrm{C}$ measurement had an erroneous clean window result. The value of $-14^{\circ} \mathrm{C}$ was obtained by assuming the clean window result for $-14^{\circ} \mathrm{C}$ and $-19^{\circ} \mathrm{C}$ would be identical. While the test is not likely to establish limits for fogged windows, it does indicate that a significant portion of the bias of Fig. 3 is due to fogging. Since fogging occurs during the heat-up portion of the run, the window is fogged by time zero in the figure. 
Table 2. Production furnace related sources of uncertainty for single color pyrometers.

\begin{tabular}{|c|c|c|}
\hline $\begin{array}{ll}\text { Source } & \text { of } \\
\text { Uncertainty }\end{array}$ & $\begin{array}{l}\text { Affect on } \\
\text { Brightness } \\
\text { Temperature } \\
\text { Measurement }\end{array}$ & Description \\
\hline $\begin{array}{l}\text { Emissivity } \\
<1.00\end{array}$ & Decrease & $\begin{array}{l}\text { In general, emissivities for metal oxides are in the range of } 0.7 \text { and } \\
\text { metals are in the range of } 0.4 .^{1 ~} 44 \text { In the furnace cavity, surfaces } \\
\text { appear to be at an emissivity of near } 1.0 \text { when all objects in the } \\
\text { furnace approach a uniform temperature at the end of a run. }\end{array}$ \\
\hline Reflection & Increase & $\begin{array}{l}\text { Surfaces with low emissivities appear more like mirrors reflecting } \\
\text { radiation of hot objects nearby. When measuring the brightness of } \\
\text { metal surfaces, the crucible radiation is reflected into the pyrometer's } \\
\text { field of view making the metal appear hotter than it actually is. The } \\
\text { increase in apparent temperature is worse for low emissivity metal } \\
\text { than for higher emissivity oxide. }\end{array}$ \\
\hline Windows & Decrease & $\begin{array}{l}\text { A window absorbs light from a target causing the brightness } \\
\text { temperature to decrease. Additionally, the two window surfaces } \\
\text { reflect some portion of the light so that it does not reach the } \\
\text { pyrometer. The decrease in brightness temperature was measured at } \\
-11.5^{\circ} \mathrm{C} \text { for } 0.34 \text {-in.-thick Pyrex } \mathrm{TM} \text { windows and }-7^{\circ} \mathrm{C} \text { for } 0.2 \text {-in. } \\
\text { thick quartz windows. Pyrex }{ }^{\mathrm{TM}} \text { windows were used when the data in } \\
\text { this section was collected. In } 1997 \text {, the Configuration Control Board } \\
\text { approved the change to quartz windows for brightness pyrometers } \\
\text { and allowed these windows to be inserted in the sight path as the } \\
\text { pyrometers are calibrated. No window error is introduced when the } \\
\text { appropriate window is used in the certification and during furnace } \\
\text { operation. }\end{array}$ \\
\hline $\begin{array}{l}\text { Window } \\
\text { Fogging }\end{array}$ & Decrease & $\begin{array}{l}\text { Window fogging occurs primarily during the heat-up portion of a run } \\
\text { when the charge outgasses. Volatile components condense on the } \\
\text { window preventing some of the target light from reaching the } \\
\text { pyrometer. Fogging causes a decrease in measured temperature for } \\
\text { brightness pyrometers because all of the target radiation in the field } \\
\text { of view must reach the detector. The magnitude of the error is } \\
\text { dependent on the amount of volatile components that condense on the } \\
\text { window and whether the window was changed out before the run. } \\
\text { In practice, the window is changed out when the operator judges } \\
\text { that it is dirty. Three estimates of the affect of window fogging were } \\
\text { obtained during this effort. The dirtiest windows from consolidation } \\
\text { runs were removed and found to cause roughly }-8,-4 \text {, and }-19^{\circ} \mathrm{C} \\
\text { errors. }\end{array}$ \\
\hline $\begin{array}{l}\text { Temperature } \\
\text { Gradients }\end{array}$ & Decrease & $\begin{array}{l}\text { Temperature gradients exist in the furnace melt. During a furnace } \\
\text { run, the crucible is heated by the induction furnace which in turn } \\
\text { heats the metal charge. The crucible is much hotter than the charge } \\
\text { during the heat-up and initial portions of the hold period. Therefore, } \\
\text { it would be expected that metal close to the rim of the crucible would } \\
\text { be hotter than at the center where the operators typically make a }\end{array}$ \\
\hline
\end{tabular}




\begin{tabular}{||l|l|l||}
\hline \hline & $\begin{array}{l}\text { measurement. Additionally, there can be gradients from the surface } \\
\text { of the metal to the bottom of the melt. Gradients, in much larger } \\
\text { furnaces, have been as large as } 4^{\circ} \mathrm{C} / \text { in. The maximum depth of melts } \\
\text { in production line addressed by this report is limited to } 1.9 \text { in. by the } \\
\text { crucible geometry. }\end{array}$ \\
\hline
\end{tabular}

Thermal gradients could account for some of the difference between optical and thermocouple temperature readings. Since the thermocouple is located closer to the crucible rim than the typical operator's reading, a slight negative error in Fig. 3 is reasonable. Additionally, gradients $\left(4^{\circ} \mathrm{C} / \mathrm{in}\right.$.) have been measured in large casters. EUO casting crucibles are limited to a melt depth of less than 1.9 in. by the crucible geometry.

Based on the data of Fig. 3, the average error introduced by Pyrex ${ }^{\mathrm{TM}}$ windows (w/o correction during calibration), window fogging, and gradients are roughly equal to $-19.4^{\circ} \mathrm{C}$. It should be noted that a gradient of about $-23^{\circ} \mathrm{C}$ was noted in large data sets collected in 1983 on a different furnace with different pyrometer certifications independent measurement instrumentation and operators. ${ }^{2}$ Therefore, the bias is well established and stable. Additionally, it is obvious that the uncertainty of measurements in the initial portion of the hold period are much larger than at the end of the hold periods. Table 3 shows the variation in mean and $2 \mathrm{~F}$ variation about the mean for various intervals in the hold period and for the entire 40-m data set. The increased variability in the early portions of the hold period are attributed to variations in emissivity and reflection.

Table 3. Mean and 2F limits for filament brightness pyrometer error in hold period.

\begin{tabular}{|l|l|l||}
\hline \hline $\begin{array}{l}\text { Time From Extrapolated Start of } \\
\text { Hold } \\
\left({ }^{\circ} \mathrm{C}\right)\end{array}$ & $\begin{array}{l}\text { Mean } \\
\left({ }^{\circ} \mathrm{C}\right)\end{array}$ & $\begin{array}{l}2 \mathrm{~F} \text { Variation } \\
\left({ }^{\circ} \mathrm{C}\right)\end{array}$ \\
\hline $0-10$ & -18.0 & 28.6 \\
\hline $11-20$ & -19.4 & 18.6 \\
\hline $21-30$ & -21.3 & 15.2 \\
\hline $31-40$ & -19.9 & 14.4 \\
\hline $0-40$ & -19.4 & 22.1 \\
\hline
\end{tabular}

Production operators take readings from the metal as opposed to oxide, which is on top of the melt (Fig. 4). If no good view of the metal is present, the operator will use the pour rod to break up the oxide layer. Metal oxides typically have an emissivity in the range of 0.7 as opposed to roughly 0.4 for metal. Since the metal with a lower emissivity appears brighter, the cause must be due to reflection from the crucible and perhaps other hot objects. When viewing oxidize, the reading is low due to the fact that the emissivity is much less than 1.0. As the hold period progresses, all surfaces become roughly the same temperature and the cavity formed by the crucible and insulation lid approximate a black body. In this condition, the variation is significantly decreased as can be seen by the drop in variation in the later portions of the hold period. Since the variation in later parts of the hold period (about " $15^{\circ} \mathrm{C}$ ) is roughly equivalent to filament pyrometers certified on strip lamp standards $\left(" 14.7^{\circ} \mathrm{C}\right)$, it is reasonable to conclude that the majority of the variation is due to pyrometer certification. Data from Fig. 3. was spread over eight months of operation, so various pyrometers were used. 


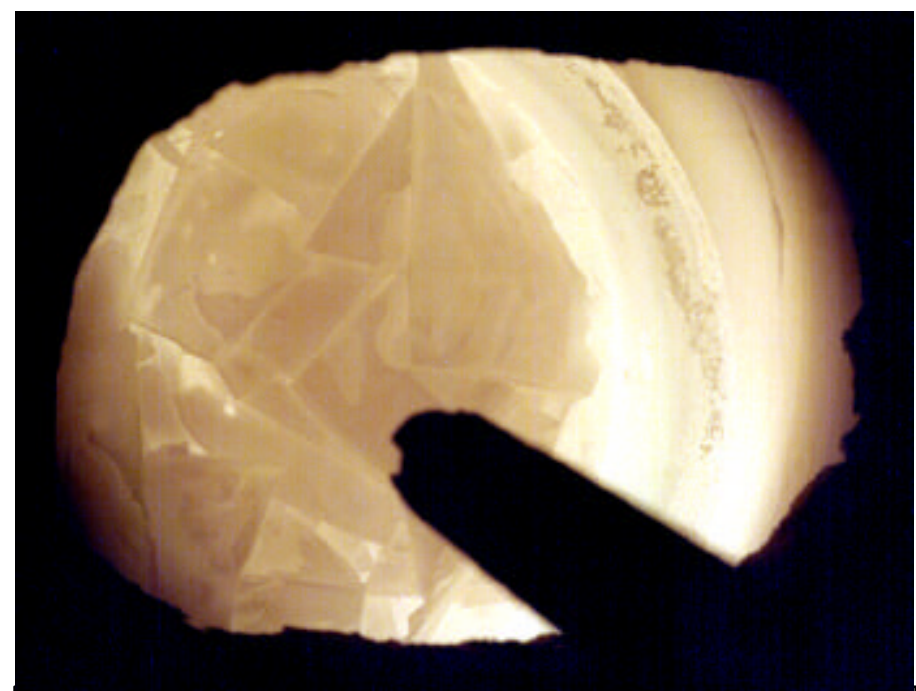

Fig. 4. Production casting furnace showing emissivity variation on the melt and a hot crucible. 


\section{CONCLUSIONS}

This work has established uncertainty limits for the EUO filament pyrometers, digital pyrometers, twocolor automatic pyrometers, and the standards used to certify these instruments (Table 1). If symmetrical limits are used, filament pyrometers calibrated in Production have certification uncertainties of not more than $\pm 20.5^{\circ} \mathrm{C}$ traceable to NIST over the certification period. Uncertainties of these pyrometers were roughly $\pm 14.7^{\circ} \mathrm{C}$ before introduction of the working standard that allowed certification in the field. Digital pyrometers addressed in this report have symmetrical uncertainties of not more than $\pm 12.7^{\circ} \mathrm{C}$ or $\pm 18.1^{\circ} \mathrm{C}$ when certified on a Y-12 Standards Laboratory strip lamp or in a production area tube furnace, respectively. Uncertainty estimates for automatic two-color pyrometers certified in Production are $\pm \mathbf{P} 6.7^{\circ} \mathrm{C}$.

Additional uncertainty and bias are introduced when measuring production melt temperatures. A $-19.4^{\circ} \mathrm{C}$ bias was measured in a large 1987 data set which is believed to be caused primarily by use of Pyrex ${ }^{\mathrm{TM}}$ windows (not present in current configuration) and window fogging. Large variability $\left(2 \sigma=28.6^{\circ} \mathrm{C}\right)$ exists in the first $10 \mathrm{~m}$ of the hold period. This variability is attributed to emissivity variation across the melt and reflection from hot surfaces. For runs with hold periods extending to $20 \mathrm{~m}$, the uncertainty approaches the calibration uncertainty of the pyrometers.

When certifying pyrometers on a strip lamp at the Y-12 Standards Laboratory, it is important to limit ambient temperature variation $\left(23 \pm 4^{\circ} \mathrm{C}\right)$, to order calibration points from high to low temperatures, to allow $6 \mathrm{~m}$ for the lamp to reach thermal equilibrium $\left(12 \mathrm{~m}\right.$ for certifications below $\left.1200^{\circ} \mathrm{C}\right)$ to minimize pyrometer bias, and to calibrate the pyrometer if error exceeds vendor specifications. A procedure has been written to assure conformance. 


\section{REFERENCES}

1. D. K. Mee, R. F. Lind, N. C. Bradley, R. M. Childs, K. J. Scott, and R. W. Tucker, "An Inside Look at Temperature Measurement Solutions from a Casting Facility", Instrument Society of America 1990 International Conference and Exhibit Proceedings, Instrument Society of America, 90-652, pp. 2047-2063, October 1990.

2. D. K. Mee, An Automatic Temperature Measurement for Casting Furnaces using an Immersion Thermocouple, Y-2287, Oak Ridge Y-12 Plant, August 1983.

3. Guidelines for Evaluating and Expressing the Uncertainty of NIST Measurement Results, NIST Technical Note 1297, National Institute of Standards and Technology, Gaithersburg, MD.

4. C. E. Gibson, Report of Calibration - Lamp Standard of Radiance Temperature for SN: P149, NIST Test No. 844/248151-91, National Institute of Standards and Technology, Gaithersburg, MD, December 16, 1991.

5. Lamps Standards of Radiance Temperature, National Institute of Standards and Technology, Gaithersburg, MD, 1991.

6. C. R. Barber, "Factors affecting the reproducibility of brightness of tungsten strip lamps for pyrometry standardization," J. Sci. Instru. 23, 238 (1946). 


\section{ACKNOWLEDGEMENTS}

The authors are grateful to numerous personnel who contributed to a better understanding of temperature measurement uncertainties over the years. Of particular importance to this work were tireless hours of data collection by R.W. Tucker, Sr. and valuable discussions with J. T. Parker and J. R. Williams about certification uncertainty. Significant credit is also due to G. R. Guinn for his vision to insert technology into the casting process. 


\section{Distribution}

Ammons, A. M., 9983-AF, MS-8194

Bird, E. L., 9202, MS-8096

Bowers, G. L., 9113, MS-8208

Boyer, D. L., 9113, MS-8208

Bryan, W. C., 9212, MS-8193

Carlson, R. V., 9113, MS-8207

Churnetski, S. R., 9202, MS-8097

Cunningham, L. B., 9212, MS-8194

DeMint, A. L., 9202, MS-8096

Elkins, J. K., 9737, MS-8091

Fisher, J. T., 9113, MS-8208

Fleenor, R. M., 9737, MS-8091

Frye, L. E., 9215-A, MS-8187

Hardrick, J. T., 9212, MS-8194

Hart, V. R., 9212, MS-8193

Hodges, R. L., 9983-AD, MS-8182

Horning, P. A., 9212, 8193

Jenkins, A. L., 9119, MS-8235

Lariviere, S. F.,9202, MS-8097

Lawson, R. L., 9203, 8084

Mee, D. K., 9203, MS-8084 (15)

Moore, A. F., 9983-AD, MS-8182

Moor, P. E., 9733-3, MS-8034

Northcutt, Jr, W. G., 9202, 8097

Pickett, C. A., 9203, MS-8084

Post, D. W., 9202, MS-8097

Prazniak, J. K., 9212, 8194

Radle, J. E., 9723-25, MS-8193 (2)

Reiner, R. H., 9202, 8097

Riepe, R. C., 9702-2, MS-8015

Seiber, L. E., NTRC, MS-6472

Sherrill, M. W., 9119, MS-8234

Tallman, M. L., 9215-A, MS-8187

Thompson, J. E., 9119, MS-8235

Thompson, Jr., J. E., 9215-A, MS-8187

Thrasher, T. H., 9113, MS-8208

Ward, G. L., 9215-A, MS-8187

Williams, J. R., 9212, MS-8193

Woodall, Jr., N. D., 9119, MS-8235

Yarborough, T. D., 9212, MS-8193

Y-12 Central Files, 9711-5, MS-8169 